\title{
Impact of coexisting multivessel coronary artery disease on short-term outcomes and long-term survival of patients treated with carotid stenting
}

Josef Veselka, Miloslav Špaček, Martin Horváth, Cyril Štěchovský, Ingrid Homolová, Petra Zimolová, Petr Hájek

Department of Cardiology, Motol University Hospital, $2^{\text {nd }}$ Medical School, Charles University, Prague, Czech Republic

Submitted: 4 November 2014

Accepted: 2 January 2015

Arch Med Sci 2016; 12, 4: 760-765

DOI: 10.5114 /aoms.2016.60964

Copyright (c) 2016 Termedia \& Banach

\section{Abstract}

Introduction: Systemic atherosclerosis can result in both coronary artery disease (CAD) and carotid artery disease. Recently it has been shown that patients with CAD have a higher incidence of microembolization during carotid artery stenting (CAS), and it has been hypothesized that they could be at higher risk in this intervention.

Material and methods: We retrospectively evaluated an institutional registry with 437 consecutive patients who underwent coronary angiography and CAS to evaluate their short-term outcomes and long-term survival with regard to the presence of coexisting multivessel coronary artery disease (MVD).

Results: We performed 220 CAS procedures in MVD patients and 318 CAS procedures in non-MVD patients. The incidence of in-hospital CAS-related adverse events was $2.7 \%$ and $2.5 \%$ in the MVD and non-MVD groups, respectively $(p=0.88)$. At 30 days, there was no significant difference between the groups in terms of the number of patients with adverse events (hierarchically death/stroke/myocardial infarction; $8.8 \%$ vs. $5.5 \% ; p=0.18$ ). The median duration of follow-up was 4.23 years. Survival free of all-cause mortality at 1,3 and 5 years was $90 \%(95 \% \mathrm{Cl}: 86-94 \%), 79 \%(95 \% \mathrm{Cl}$ : 73-85\%) and $70 \%(95 \% \mathrm{Cl}: 64-77 \%)$, and $92 \%(95 \% \mathrm{Cl}: 89-95 \%), 85 \%$ (95\% Cl: $80-90 \%)$ and $76 \%(95 \% \mathrm{Cl}: 70-82 \%)$ for the MVD and non-MVD groups $(p=0.02)$, respectively.

Conclusions: These results suggest that patients with MVD combined with carotid artery disease are probably not at higher risk of early post-CAS adverse clinical events, but they have significantly worse long-term survival rates.

Key words: carotid disease, stenting, survival.

\section{Introduction}

Systemic atherosclerosis can result in both coronary artery disease (CAD) and carotid artery disease. It has been demonstrated that CAD is the most common concomitant vascular disease in patients with significant carotid artery disease [1]. In addition, it is known that multivessel CAD can negatively influence the long-term survival of affected patients [2].

Carotid artery stenting (CAS) is a therapeutic alternative to endarterectomy in patients with significant stenosis $[3,4]$. However, there is an

\author{
Corresponding author: \\ Josef Veselka MD, PhD \\ Department of Cardiology \\ University Hospital Motol \\ $2^{\text {nd }}$ Medical School \\ Charles University \\ V úvalu 84 \\ 15000 Prague 5 \\ Czech Republic \\ E-mail: veselka.josef@ \\ seznam.cz
}


ongoing debate concerning the procedural safety of this intervention, the long-term outcomes, and most notably about the selection of appropriate patients for transcatheter therapy [4]. On the other hand, an increasing number of interventional cardiologists perform CAS in their daily practice, and some of their patients also suffer from CAD. Recently, it has been shown that patients with CAD have a higher incidence of peri-CAS microembolization, and it has been hypothesized that they could be at higher risk in this intervention [1]. Therefore, in this retrospective study we report the short- and long-term outcomes of patients treated with stenting for carotid artery disease with regard to the presence of multivessel CAD (MVD).

\section{Material and methods}

\section{Study population}

Between September 2005 and September 2014,437 consecutive patients ( $69 \pm 9$ years, $65 \%$ males) with CAS were enrolled. All these patients had a history of angina pectoris and/or a pathological result on an exercise test, which was followed by coronary angiography. They were also examined by transcranial Doppler ultrasound, duplex ultrasound and/or computed tomography (CT) angiography of the carotid arteries for carotid murmur, central symptoms or high risk of peripheral atherosclerotic disease. Based on non-invasive examination, they were referred for carotid angiography and subsequently for CAS. Generally, CAS was performed in patients with significant stenosis who were poor candidates for general anesthesia, at high risk or technically difficult for endarterectomy, or who had radiation-related carotid stenosis or restenosis after endarterectomy or CAS. A total of 100 carotid endarterectomies were performed during the study period.

An optimal carotid and coronary revascularization strategy was tailored for each patient; we preferred a staged approach with treatment of symptomatic coronary or carotid lesions first and subsequent revascularization of the stable lesion. In exceptional cases, with both coronary and carotid symptomatic lesions, we used simultaneous revascularization.

A total of 538 consecutive CAS procedures using different stents and distal or proximal embolic protective devices were performed. Data for each CAS procedure and outcomes of the patients were prospectively collected and then retrospectively reviewed. Eligible patients were divided into two groups according to the baseline presence or absence of MVD (Tables I and II). Half of the patients in the non-MVD group had single-vessel CAD.

Written informed consent was obtained from each patient, and the local ethics committee (Eth- ics Committee for Multi-Centric Clinical Trials) approved all study protocols.

\section{Definitions}

All carotid stenoses were quantified angiographically according to NASCET criteria [5]. Patients treated with CAS had to be symptomatic with $50-99 \%$ stenosis or asymptomatic with 7099\% stenosis.

Coronary stenoses $>50 \%$ were considered significant at angiography. Borderline lesions were examined by fractional flow reserve. The coronary artery tree was divided into three compartments (left anterior descending artery, left circumflex artery, and right coronary artery) for the categorization of one-, two-, and three-vessel CAD. Two- and three-vessel CAD was considered MVD.

Minor stroke was defined as a new neurological deficit that resolved completely or returned to baseline within 30 days, and major stroke was defined as cases in which symptoms persisted for $>30$ days. Post-CAS myocardial infarction was defined by an elevated troponin level that was elevated three times above the upper limit of the normal range in addition to cardiac symptoms within 30 days after CAS.

\section{Procedure}

The CAS was performed as described elsewhere [6-8]. All procedures were performed via the femoral approach using a $7 \mathrm{Fr}$ or $8 \mathrm{Fr}$ guiding catheter, a 6 Fr guiding sheath or a 9 Fr Moma System. The type of stent and type of embolic protection device were chosen at the discretion of the primary operator. In patients referred for bilateral CAS, the subsequent intervention was usually performed several weeks after the first.

On the day of the procedure, all patients were repeatedly examined by nursing staff and physicians. All symptomatic patients were examined by board-certified neurologists, and the examination included a CT scan of the brain. Asymptomatic patients were discharged on the next day. Electrocardiography was performed before CAS, as well as 1 and $12-16$ h thereafter. Cardiac biomarkers were measured only in patients with cardiac symptoms.

\section{Follow-up}

All patients were asked to undergo clinical examination at 30 days. All patients with CAD were treated according to guidelines on myocardial revascularization [9]. Survival was confirmed by reviewing the national database of the deceased.

\section{Statistical analysis}

Two independent statisticians were responsible for the data collection and statistical analysis. 
Table I. Patient characteristics

\begin{tabular}{|c|c|c|c|}
\hline Parameter & $\begin{array}{c}\text { MVD } \\
(n=182)\end{array}$ & $\begin{array}{l}\text { Non-MVD } \\
(n=255)\end{array}$ & $P$-value \\
\hline \multicolumn{4}{|l|}{ Age [years]: } \\
\hline Mean \pm SD & $68 \pm 7.9$ & $69 \pm 8.8$ & 0.118 \\
\hline Range & $47.5-89.5$ & $23.9-91.2$ & \\
\hline Men (\%) & 77 & 56 & $<0.001$ \\
\hline Angina pectoris (\%) & 33 & 7 & $<0.001$ \\
\hline Dyspnea, NYHA class > 1 (\%) & 49 & 25 & $<0.001$ \\
\hline Previous myocardial infarction (\%) & 51 & 18 & $<0.001$ \\
\hline Current smokers (\%) & 30 & 40 & 0.044 \\
\hline Hypertension (\%) & 96 & 90 & 0.026 \\
\hline Total plasma cholesterol [mmol/l; mg/dl] & $\begin{array}{c}4.2 \pm 0.9 \\
162.4 \pm 34.8\end{array}$ & $\begin{array}{c}4.4 \pm 1.0 \\
170.1 \pm 38.7\end{array}$ & 0.131 \\
\hline LDL cholesterol [mmol/l; mg/dl] & $\begin{array}{c}2.4 \pm 0.7 \\
92.8 \pm 27.1\end{array}$ & $\begin{array}{c}2.5 \pm 1.4 \\
96.7 \pm 54.1\end{array}$ & 0.647 \\
\hline HDL cholesterol [mmol/l; mg/dl] & $\begin{array}{c}1.0 \pm 0.3 \\
38.7 \pm 11.6\end{array}$ & $\begin{array}{c}1.1 \pm 0.3 \\
42.5 \pm 11.6\end{array}$ & 0.002 \\
\hline Plasma triglyceride $[\mathrm{mmol} / \mathrm{l} ; \mathrm{mg} / \mathrm{dl}]$ & $\begin{array}{c}1.8 \pm 1.0 \\
159.4 \pm 88.6\end{array}$ & $\begin{array}{c}1.8 \pm 1.1 \\
159.4 \pm 97.4\end{array}$ & 0.726 \\
\hline Diabetes mellitus (\%) & 54 & 38 & 0.008 \\
\hline Renal failure (\%) & 27 & 19 & 0.030 \\
\hline Severe bronchopulmonary disease (\%) & 20 & 11 & 0.015 \\
\hline Need for open heart surgery within 30 days (\%) & 25 & 2 & $<0.001$ \\
\hline Previous coronary artery intervention (\%) & 50 & 16 & $<0.001$ \\
\hline Previous stroke (\%) & 29 & 45 & 0.005 \\
\hline Cerebral ischemic symptoms in the last month (per procedure) (\%) & 14 & 31 & $<0.001$ \\
\hline Pre-procedural statin (\%) & 88 & 70 & $<0.001$ \\
\hline Pre-procedural ACE inhibitor (\%) & 80 & 65 & 0.006 \\
\hline Pre-procedural $\beta$-blocker (\%) & 82 & 52 & $<0.001$ \\
\hline
\end{tabular}

Table II. Interventional and angiographic characteristics of the study population

\begin{tabular}{|lccc|}
\hline Variable & $\begin{array}{c}\text { MVD } \\
(n=220)\end{array}$ & $\begin{array}{c}\text { Non-MVD } \\
(n=318)\end{array}$ & $P$-value \\
\hline Lesion located in LICA/RICA (\%) & $50 / 50$ & $53 / 47$ & 0.566 \\
\hline Stenosis 90-99\% (\%) & 37 & 40 & 0.486 \\
\hline Tandem lesion (\%) & 19 & 18 & 0.803 \\
\hline Stenosis before procedure & $82.1 \pm 10.1$ & $82.2 \pm 10.2$ & 0.971 \\
\hline Stenosis after procedure & $9.7 \pm 10.5$ & $11.3 \pm 13.3$ & 0.233 \\
\hline Contralateral occlusion (\%) & 8 & 13 & 0.030 \\
\hline Contrast medium [ml] & $130 \pm 46$ & $123 \pm 39$ & 0.168 \\
\hline Direct stenting (\%) & 87 & 81 & 0.058 \\
\hline Mean stent length [mm] & $38 \pm 11$ & $36 \pm 13$ & 0.827 \\
\hline Atropine during procedure (\%) & 46 & 51 & 0.264 \\
\hline Number of post-dilations & $1.1 \pm 0.6$ & $1.1 \pm 0.8$ & 0.068 \\
\hline Fluoroscopic time, median (range) [min] & $6.7(2.5-27.0)$ & $7.0(2.5-31.5)$ & 0.199 \\
\hline Bilateral stenoses (\%) & 47 & 56 & 0.047 \\
\hline
\end{tabular}


Normally distributed data are presented as means \pm standard deviation ( \pm SD) and non-normally distributed data as medians with interquartile range (IQR). The distribution of data was evaluated using the Kolmogorov-Smirnov test. Student's t-tests, Wilcoxon tests, Fisher tests, and Kaplan-Meier survival analysis were used when appropriate. The first procedure was the index procedure for survival analysis. The Cox proportional hazards regression was used to identify predictors of longterm all-cause mortality. The following pre-specified variables were evaluated, first in a univariate model: age, sex, renal failure (plasma creatinine $>130 \mu \mathrm{mol} / \mathrm{l})$, diabetes, symptoms in the last 6 months, bilateral carotid artery disease, and MVD. Variables with a $p$-value $<0.15$ were then entered into a multivariate analysis, which was performed using a backward stepwise multiple Cox regression. A probability $<0.05$ was considered statistically significant. We used the statistical software Stata, release 9.2 (StataCorp LP, College Station, TX, USA).

\section{Results}

\section{Patient and procedural characteristics}

Overall, we implanted 544 stents in 538 procedures: 220 CAS procedures and 318 CAS procedures in patients with MVD and non-MVD patients, respectively. Technical success with residual stenosis $\leq 30 \%$ was achieved in $98 \%$ of cases. Embolic protective systems were used in 519 (96\%) procedures; in $54(10 \%)$ cases the proximal protective system was used, and in 465 (90\%) cases the distal protective system was used. Carotid artery stenting was combined with percutaneous coronary intervention in 15 cases (3\%) and with coronary angiography in 69 (13\%) cases. Patient and procedural characteristics are presented in Tables I and II. The incidence of in-hospital CAS-related adverse events was $2.7 \%$ (1 death and 5 strokes) and $2.5 \%$ (1 death and 7 strokes) per each procedure in the MVD and non-MVD groups, respectively $(p=0.88)$. All discharged patients have taken the optimal medical therapy including aspirin and statins.

Table III. Adverse events during 30-day follow-up

\begin{tabular}{|lccc|}
\hline Variable & $\begin{array}{c}\text { MVD } \\
(n=182)\end{array}$ & $\begin{array}{c}\text { Non-MVD } \\
(n=255)\end{array}$ & $P$-value \\
\hline Death (\%) & $5(2.7)$ & $2(0.8)$ & 0.107 \\
\hline Major stroke (\%) & $4(2.2)$ & $4(1.6)$ & 0.629 \\
\hline Minor stroke (\%) & $6(3.3)$ & $8(3.1)$ & 0.926 \\
\hline $\begin{array}{l}\text { Myocardial } \\
\text { infarction (\%) }\end{array}$ & $1(0.5)$ & 0 & 0.236 \\
\hline Total (\%) & $16(8.8)$ & $14(5.5)$ & 0.179 \\
\hline
\end{tabular}

\section{Thirty-day follow-up}

The clinical follow-up at 30 days was completed in all patients. A total of 135 (74\%) patients and 39 (15\%) patients were treated with percutaneous coronary intervention or coronary artery bypass in the MVD and non-MVD groups, respectively. The outcomes of the short-term follow-up are summarized in Table III. There was no significant difference between the groups in the number of patients with adverse events (hierarchically death or stroke or myocardial infarction; $8.8 \%$ vs. $5.5 \% ; p=0.18$; retrospective power 0.2).

\section{Survival}

Survival data were available for all patients, and the median duration of follow-up was 4.23 years (IQR: 1.9-6.4 years); median follow-up was 4.29 years (IQR: 1.7-6.8 years) and 4.23 (IQR: 2.1-6.3 years) in the MVD and non-MVD groups, respectively. A total of 119 (27\%) deaths occurred during 1847 patient-years, which means an overall mortality rate of $6.4 \%$ per year.

Survival free of all-cause mortality at one, three and five years was 90\% (95\% Cl: 86-94\%), 79\% (95\% Cl: 73-85\%) and 70\% (95\% Cl: 64-77\%), and 92\% (95\% Cl: 89-95\%), 85\% (95\% Cl: 80-90\%) and $76 \%(95 \% \mathrm{Cl}: 70-82 \%)$ for the MVD and nonMVD groups ( $p=0.02$ ), respectively (Figure 1 ).

According to multivariate analysis, the independent predictors of all-cause mortality were renal failure (hazard ratio 2.04, 95\% Cl: 1.38-3.03; $p<0.01$ ), presence of MVD (hazard ratio 1.53 , 95\% Cl: $1.06-2.22 ; p=0.03$ ), bilateral CAD (hazard ratio $1.44,95 \% \mathrm{Cl}: 1-2.07 ; p=0.05)$, and age at the time of CAS (hazard ratio $1.04,95 \% \mathrm{Cl}$ : $1.02-1.06 ; p<0.01)$.

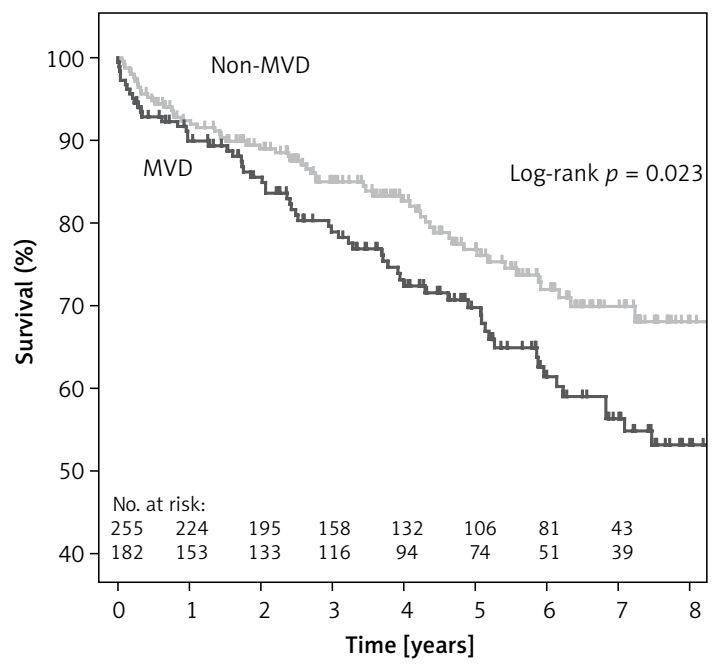

Figure 1. Kaplan-Meier survival curves for all-cause mortality in patients after carotid stenting with and without multivessel coronary artery disease (MVD) 


\section{Discussion}

To the best of our knowledge, this is the first study to address short-term clinical outcomes and long-term survival in CAS patients considering the severity of baseline CAD. The principal findings of the study are as follows: i) CAS was safe in both groups of patients, ii) patients with MVD were at similar risk of early post-CAS adverse events, but they had worse long-term survival than non-MVD patients, iii) renal failure, MVD, bilateral carotid artery disease, and higher age at the time of CAS were independent predictors of higher long-term all-cause mortality.

One of the most important features of atherosclerosis is its systemic and progressive character. Therefore, patients with carotid atherosclerosis are likely to experience not only stroke, but also myocardial infarction and cardiovascular-related death [1]. It seems to be logical that while a history of recent stroke, clinical presentation, carotid lesion-related factors, and aortic arch/carotid anatomy [10] are associated with the occurrence of peri-procedural complications and short-term outcomes of CAS patients, any pre-existing comorbidities, including the extent of coronary atherosclerosis, determine long-term survival [11-14]. However, based on a presumption that patients with CAD also have a greater extent of peripheral atherosclerosis, Chung et al. reported a higher number of periprocedural CAS embolizations in patients with a history of myocardial infarction [13]. Also, Chung et al. demonstrated that the extent of CAD positively correlates with post-CAS ischemic lesions on diffusion-weighted imaging scanning [15]. Nevertheless, in this study we did not find any difference in CAS-related adverse events between patients with and without MVD. Thus, these results suggest that a potentially higher incidence of microembolization during CAS associated with a greater extent of coronary atherosclerosis cannot be directly translated into clinical events.

Most studies to date have focused on the short-term outcomes of CAS patients, and longterm survival data are not numerous in the literature. In this study, the annual mortality rate was $6.4 \%$, compared to $2.3 \%$ in the TARGET-CAS trial (mean age at CAS 65 years, mean follow-up: 23 months) [16], 3.4\% in the multi-center European study (mean age at CAS 72 years, mean follow-up: 32 months) [17], 3.6\% in the Italian study (mean age at CAS 71.5 years, mean follow-up 33 months) [18], and $5.4 \%$ in the Austrian trial (Linz group: mean age at CAS 71 years, median follow-up: 6.5 years) [19]. These comparisons suggest that the patients included in our study were at high risk for long-term survival. Hoke et al. stratified CAS patients into tertiles according to weighted risk score and observed 5 -year survival of $91 \%, 73 \%$, and $48 \%$ in the first, second, and third tertiles, respectively [19]. Our patients had a 5-year survival rate of $70 \%$ and $76 \%$ in the MVD and nonMVD groups, respectively, which correlates with the second tertile of the above-mentioned study. Also, a nearly identical 5 -year survival rate of $70 \%$ was documented in the recent study by Kang et al. in carotid artery patients treated with endarterectomy [20]. The most probable explanation for the long-term high risk of our CAS patients is their systemic atherosclerosis, due to which they are referred to cardiologists. In line with this hypothesis, we found that the independent risk factors for long-term survival also included the presence of MVD (hazard ratio: 1.5). Interestingly, a similar relationship between the extent of coronary atherosclerosis and survival was demonstrated in patients with severe CAD treated with coronary bypasses (hazard ratio 1.9 for triple-vessel disease, 1.4 for double-vessel disease) [21]. Similarly, bilateral carotid atherosclerosis and renal failure were demonstrated to be both significant predictors of survival in this study and also predictors of cardiovascular risk in patients after carotid endarterectomy in another recently published study [22]. Thus, based on our results, one must be cautious when prescribing CAS for asymptomatic carotid patients with multiple risk factors (including MVD), and the benefit of this interventional procedure over medical treatment should carefully be evaluated; it is recommended that eligible CAS patients should be $\leq 75$ years old and have a life expectancy $\geq 5$ years $[23,24]$.

Because there are some limitations in our study, the results should be interpreted cautiously. First, there are some inherent limitations in the retrospective analysis of a single-center registry. Second, this study was focused on survival. Therefore, we did not analyze the long-term protective effect of CAS against ipsilateral stroke. However, these analyses have been performed previously and showed similar efficacy for CAS and endarterectomy [25]. Third, the study was underpowered for short-term results. Fourth, we were not able to establish causes of death in the study population.

In conclusion, these results suggest that patients with multi-vessel CAD combined with carotid artery disease treated with CAS are probably not at higher risk of early adverse clinical events associated with the carotid stenting procedure, but they have significantly worse long-term survival rates than those with no or single-vessel CAD.

\section{Acknowledgments}

The authors are grateful to Eva Hansvenclová and Marek Malý, PhD, for their assistance with the statistical analysis. 
The study was supported by grant no. 00064203 from the Ministry of Health of the Czech Republic.

\section{Conflict of interest}

The authors declare no conflict of interest.

\section{References}

1. Huang KL, Chang YJ, Chang CH, et al. Impact of coexisting coronary artery disease on the occurrence of cerebral ischemic lesions after carotid stenting. PloS One 2014; 14: e94280.

2. Appleby CE, Mackie K, Dzavik V, Ivanov J. Late outcomes following percutaneous coronary interventions: results from a large observational registry. Can J Cardiol 2010; 26: e218-24.

3. Saw J. Carotid artery stenting for stroke prevention. Can J Cardiol 2014; 30: 22-34.

4. Almekhlafi MA, Morrish WF, Hill MD. Carotid artery stenting: the dust has not yet settled. Can J Cardiol 2014; 30: 14-5.

5. North American Symptomatic Carotid Endarterectomy Trial Collaborators (NASCET). Beneficial effect of carotid endarterectomy in symptomatic patients with highgrade carotid stenosis. N Engl J Med 1991; 325: 445-53.

6. Veselka J, Černá D, Zimolová P, et al. Thirty-day outcomes of direct carotid artery stenting with cerebral protection in high-risk patients. Circ J 2007; 71: 1468-72.

7. Spacek M, Veselka J. Carotid artery stenting - current status of the procedure. Arch Med Sci 2013; 9: 1028-31.

8. Veselka J, Černá D, Zimolová P, et al. Feasibility, safety and early outcomes of direct carotid artery stent implantation with use of the FilterWire EZTM Embolic Protection System. Catheter Cardiovasc Interv 2009; 73: 733-8.

9. Windecker S, Kohl P, Alfonso F, et al. 2014 ESC/EACTS Guidelines on myocardial revascularization: The Task Force on Myocardial Revascularization of the European Society of Cardiology (ESC) and the European Association for Cardio-Thoracic Surgery (EACTS) developed with the special contribution of the European Association of Percutaneous Cardiovascular Interventions (EAPCI). Eur Heart J 2014; 35: 2541-619.

10. Spacek M, Veselka J. Bovine arch. Arch Med Sci 2012; 8: 166-7.

11. Veselka J, Zimolová P, Špaček $M$, et al. Comparison of carotid artery stenting in patients with single versus bilateral carotid artery disease and factors affecting midterm outcome. Ann Vasc Surg 2011; 25: 796-804.

12. Veselka J, Spacek M, Homolova I, Zimolova P. Obesity paradox in female patients after stent implantation for carotid artery disease. Int I Cardiol 2014; 172: 600-1.

13. Veselka J, Zimolova P, Martinkovicova L, et al. Comparison of mid-term outcomes for carotid artery stenting for moderate versus critical stenosis. Arch Med Sci 2012; 8: 75-80.

14. Van Lammeren GW, Catanzariti LM, Peelen LM, et al. Clinical prediction rule to estimate the absolute 3-year risk of major cardiovascular events after carotid endarterectomy. Stroke 2012; 43: 1273-8.

15. Chung C, Shah TR, Shin H, et al. Determinants of embolic risk during angioplasty and stenting: neurologic symptoms and coronary artery disease increase embolic risk. Ann Surg 2010; 252: 618-24.

16. Pieniazek P, Musialek P, Kanlak-Ziembicka A, et al. Carotid artery stenting with patient- and lesion-tailored selection of the neuroprotection system and stent type: early and 5 -year results from a prospective academic registry of 535 consecutive procedures (TARGET-CAS). J Endovasc Ther 2008; 15: 249-62.

17. De Donato G, Setacci C, Deloose K, Peeters P, Cremonesi A, Bosiers $M$. Long-term results of carotid artery stenting. J Vasc Surg 2008; 48: 1431-41.

18. De Rango P, Parlani G, Verzini F, et al. Long-term prevention of stroke. J Am Coll Cardiol 2011; 57: 664-71.

19. Hoke M, Ljubuncic E, Steinwender C, et al. A validated risk score to predict outcomes after carotid stenting. Circ Cardiovasc Interv 2012; 5: 841-9.

20. Kang J, Conrad MF, Patel VI, et al. Clinical and anatomic outcomes after carotid endarterectomy. I Vasc Surg 2014; 59: 944-9.

21. Van Domburg RT, Kappetein AP, Bogers JJC. The clinical outcome after coronary bypass surgery: a 30-year follow-up study. Eur Heart J 2009; 30: 453-8.

22. Van Lammeren GW, Catanzariti LM, Peelen LM, et al. Clinical prediction rule to estimate the absolute 3-year risk of major cardiovascular events after carotid endarterectomy. Stroke 2012; 43: 1273-8.

23. Chatuverdi S, Bruno A, Feasby T, et al. Therapeutics and Technology Assessment Subcommittee of American Academy of Neurology. Carotid endarterectomy - an evidence based review: report of the Therapeutics and Technology Assessment Subcommittee of the American Academy of Neurology. Neurology 2005; 65: 794-801.

24. Wrobel W, Lesiak M, Sinkiewicz A. Fracture of a carotid stent and restenosis of common carotid artery. Arch Med Sci 2013; 9: 953-6.

25. Brott TG, Hobson RW, Howard G, et al. Stenting versus endarterectomy for treatment of carotid-artery stenosis. New Engl J Med 2010; 363: 11-23. 